\title{
Optimization of synergism of a recombinant auxiliary activity 9 from Chaetomium globosum with cellulase in cellulose hydrolysis
}

\author{
In Jung Kim ${ }^{1}$ - Ki Hyun $\mathrm{Nam}^{2}$ • Eun Ju Yun ${ }^{1}$ Sooah Kim ${ }^{1}$ - Hak Jin Youn ${ }^{1}$. \\ Hee Jin Lee ${ }^{1} \cdot$ In-Geol Choi ${ }^{1} \cdot$ Kyoung Heon Kim ${ }^{1}$
}

Received: 7 February 2015 /Revised: 14 March 2015 / Accepted: 1 April 2015 / Published online: 5 May 2015

(C) The Author(s) 2015. This article is published with open access at Springerlink.com

\begin{abstract}
Auxiliary activity family 9 (AA9, formerly known as glycoside hydrolase family 61 or polysaccharide monooxygenase) is a group of fungal proteins that were recently found to have a significant synergism with cellulase in cellulose hydrolysis via the oxidative cleavage of glycosidic bonds of cellulose chains. In this study, we report the active expression of a recombinant fungal AA9 from Chaetomium globosum (CgAA9) in a bacterial host, Escherichia coli, and the optimization of its synergistic activity in cellulose hydrolysis by using cellulase. The recombinant $C g A A 9(0.9 \mathrm{mg} / \mathrm{g}$ cellulose) exhibited 1.7-fold synergism in the hydrolysis of Avicel when incubated with 0.9 filter paper units of Celluclast $1.5 \mathrm{~L} / \mathrm{g}$ cellulose. The first study of the active expression of AA9 using a bacterial host and its synergistic optimization could be useful for the industrial application of AA9 for the saccharification of lignocellulose.
\end{abstract}

Keywords AA9 - GH61 - Synergism · Cellulose hydrolysis · Cellulase $\cdot$ Chaetomium globosum

Electronic supplementary material The online version of this article (doi:10.1007/s00253-015-6592-3) contains supplementary material, which is available to authorized users.

Kyoung Heon Kim

khekim@korea.ac.kr

1 Department of Biotechnology, Korea University Graduate School, Seoul 136-713, Republic of Korea

2 Pohang Accelerator Laboratory, Pohang University of Science and Technology, Pohang 790-784, Republic of Korea

\section{Introduction}

Lignocellulose is a promising feedstock for the production of biofuels or biochemicals. Due to the inherent recalcitrance of lignocellulose, its enzymatic hydrolysis, a key step to obtain fermentable sugar, is considered as a bottleneck in biofuel production (Lynd et al. 2008). Many efforts have been made to develop an efficient hydrolysis method for cellulose, which include the exploitation of synergism among proteins in cellulose hydrolysis (Arantes and Saddler 2010). The role of nonhydrolytic proteins in cellulose hydrolysis was proposed in the $\mathrm{C}_{1}-\mathrm{C}_{\mathrm{x}}$ model several decades ago, in which the $\mathrm{C}_{1}$ factor (non-hydrolytic protein) acts as an enhancing protein for the $C_{x}$ factor (hydrolytic enzyme) (Din et al. 1994; Gilligan and Reese 1954; Reese et al. 1950). Synergism between nonhydrolytic proteins and hydrolytic enzymes has been observed with carbohydrate-binding modules (CBMs), bacterial expansin, swollenin, and auxiliary activity 9 (AA9) (Dimarogona et al. 2012; Din et al. 1991; Harris et al. 2010; Kim et al. 2009; Lin et al. 2013; Suwannarangsee et al. 2012; Zhou et al. 2011).

AA9, formerly known as glycoside hydrolase family 61 (GH61) or polysaccharide monooxygenase (PMO), is a recently discovered and newly classified enzyme family in the Carbohydrate-Active enZymes (CAZy) database (Levasseur et al. 2013; Lombard et al. 2014). The AA9 proteins are widespread in cellulolytic fungi and have been shown to play a crucial role in cellulose degradation (Harris et al. 2010; Vaaje-Kolstad et al. 2010). It has been found that fungal AA9 and AA10 (CBM33) possess synergistic activity with cellulase and act by chemically modifying cellulose (Forsberg et al. 2011; Langston et al. 2011; Phillips et al. 2011a; Quinlan et al. 2011; Vaaje-Kolstad et al. 2010).

The cleavage action of the AA9 on cellulose requires a metal cofactor for activity and takes place via an 
oxidoreductive mechanism, yielding oxidized oligosaccharides at their reducing (aldonic acids) or non-reducing ends (4-ketoaldose in the case of $\mathrm{C}_{4}$ oxidation) (Beeson et al. 2012; Forsberg et al. 2011; Langston et al. 2011; Phillips et al. 2011a; Quinlan et al. 2011; Vaaje-Kolstad et al. 2010; Westereng et al. 2011). Due to their oxidoreductive action, cleavage reactions by AA9s are performed in the presence of electron donors such as ascorbic acid, reduced glutathione, or gallate (Beeson et al. 2012; Forsberg et al. 2011; Langston et al. 2011; Phillips et al. 2011a; Quinlan et al. 2011; VaajeKolstad et al. 2010; Westereng et al. 2011). This oxidoreductive action on cellulose is exemplified by AA9s from Thermoascus aurantiacus (TaGH61A) (Quinlan et al. 2011), Phanerochaete chrysosporium (PcGH61D) (Westereng et al. 2011), and Neurospora crassa (NcPMO-1 and NcPMO-2) (Beeson et al. 2012; Phillips et al. 2011b). AA9 proteins are hypothesized to recognize the crystalline surface of cellulose for cleavage ahead of the action of classical hydrolases, thus expressing synergism with cellulase (Quinlan et al. 2011). The first report on the synergistic activity of AA9 with cellulase was shown with TaGH61A and TtGH61E (Harris et al. 2010); these proteins exhibited 1.3-fold and 1.1-fold synergistic activities with Trichoderma reesei cellulases on lignocellulose at $\sim 70 \%$ of the cellulose hydrolysis level. However, the synergistic activities of TaGH61A and $T t \mathrm{GH} 61 \mathrm{E}$ were not observed on pure cellulose at cellulose hydrolysis levels over $\sim 70 \%$ glucose yield (Harris et al. 2010). Furthermore, in other studies, various AA9s such as StCel61 A from Sporotrichum thermophile (Dimarogona et al. 2012), PcGH61D from $P$. chrysosporium (Westereng et al. 2011), and AA10 from Streptomyces coelicolor A3 (2) (Forsberg et al. 2011) showed synergism with cellulase in the hydrolysis of lignocellulose or pure cellulose. The synergistic activities of AA9s significantly differ depending on the type of substrate (lignocellulose vs. pure cellulose) and the genetic source of AA9.

To date, among the numerous AA9s that are widespread in fungi, only a few AA9s have been functionally characterized (Dimarogona et al. 2012; Forsberg et al. 2011; Harris et al. 2010; Westereng et al. 2011). Moreover, only AA10, which originates from a bacterium, has been actively expressed in a bacterial host (Forsberg et al. 2011; Vaaje-Kolstad et al. 2010). Other AA9s of fungal origin have not been reported to date as being actively expressed in bacterial hosts (Bey et al. 2013; Dimarogona et al. 2012; Harris et al. 2010; Phillips et al. 2011a; Westereng et al. 2011). In addition, no study has been published on the systematic optimization of reaction conditions for AA9 synergism. Efforts are needed towards the identification and functional study of additional AA9s that can be actively expressed in bacterial hosts and optimization of their synergistic activities.

Chaetomium globosum, a soil fungus belonging to ascomycetes, recently received much attention due to its high cellulolytic activity (Lakshmikant and Mathur 1990; Longoni et al. 2012). In particular, the AA9-encoding genes of C. globosum were found to be highly expressed when grown on cellulosic substrates (Longoni et al. 2012). Here, we report the first AA9 from C. globosum ( $C g \mathrm{AA}$ 9) that is functionally active as a synergistic protein for cellulase. We have investigated the synergistic activity of recombinant $C g A A 9$, produced in Escherichia coli, on cellulose. The active expression of fungal AA9 in a bacterial host and its synergistic optimization in our study will pave the way for further studies on AA9s and their industrial applications.

\section{Materials and methods}

\section{Reverse transcription polymerase chain reaction}

The fungal strain C. globosum CBS 148.51 was obtained from the Rural Development Administration, Suwon, Korea. A single colony of $C$. globosum was cut into a circle with a $1-\mathrm{cm}$ diameter, and the cut circle was inoculated into $20 \mathrm{~mL}$ malt extract broth. After cultivation for $19 \mathrm{~h}, 1 \mathrm{~mL}$ seed culture was inoculated into $100 \mathrm{~mL}$ medium containing $0.5 \%(w / v)$ carbon source (glucose or Avicel), $0.2 \%(w / v) \mathrm{NaNO}_{3}, 0.1 \%(w /$ v) $\mathrm{KH}_{2} \mathrm{PO}_{4}, 0.05 \%(w / v) \mathrm{MgSO}_{4} \cdot 7 \mathrm{H}_{2} \mathrm{O}, 0.05 \%(w / v) \mathrm{KCl}$, and $0.001 \%(w / v) \mathrm{FeSO}_{4} \cdot 7 \mathrm{H}_{2} \mathrm{O}$. Fungal hyphae were harvested from $100 \mathrm{~mL}$ culture by filtering through a filtration cloth (22-25 $\mu \mathrm{m}$; Calbiochem, La Jolla, CA) and then washed with distilled water to remove residual medium components. The filtered hyphae were ground by a mortar and pestle under liquid nitrogen. The ground hyphae were disrupted by sonication to extract total RNA using an RNA isolation kit (SigmaAldrich, St. Louis, MO). The integrity of the extracted RNA was confirmed on agarose gel electrophoresis, and a complementary DNA (cDNA) library was constructed from $1 \mu \mathrm{g}$ of total RNA using Maxime RT PreMix containing oligo dT primers (Intron Biotechnology, Seoul, Korea) following the manufacturer's instructions. A cDNA library was constructed by incubating the reaction mixture at $45^{\circ} \mathrm{C}$ for $60 \mathrm{~min}$, followed by the inactivation of reverse transcriptase at $95{ }^{\circ} \mathrm{C}$ for 5 min. The genes for $C g A A 9$ (CHGG_09805; GenBank accession no. EAQ83401) and histone H4.2 (GenBank accession no. EAQ83894) as the control were amplified by the polymerase chain reaction (PCR) using gene-specific primers. The sequences of the forward and backward primers for $\mathrm{Cg}$ AA9 and histone H4.2 were 5'-GAAGGAGATATAAGGATG CACTACACCTTCCCGAGGCTA-3' and 5'-ATGATGGTG ATGGTGAGCCGCTCCACACGGCCGGTC-3', and 5'ACTGGACGCGGAAAGGGCGG-3' and 5'-GCCGCCGA AGCCGTAGAGAGT-3', respectively. PCR was performed using SolgTM 2× Taq PCR smart mix 2 (SolGent, Daejeon, Korea) by the following program: 1 cycle at $95^{\circ} \mathrm{C}$ for $2 \mathrm{~min}$, 35 cycles including three steps for each cycle $\left(95^{\circ} \mathrm{C}\right.$ for $20 \mathrm{~s}$, 
$51^{\circ} \mathrm{C}$ for $40 \mathrm{~s}$, and $72{ }^{\circ} \mathrm{C}$ for $1 \mathrm{~min}$ ), and one final cycle at $72^{\circ} \mathrm{C}$ for $5 \mathrm{~min}$. The transcript level was qualitatively visualized on a $0.8 \%(w / v)$ agarose gel.

\section{Sequence alignment and structural modeling}

The sequence alignment of $C g \mathrm{AA} 9$ (GenBank accession no. EAQ83401), TaGH61A (GenBank no. ACS05720) from T. aurantiacus, TtGH61E (GenBank no. ACE10234) from Thielavia terrestris, HjGH61B (GenBank no. AY281372) from Hypocrea jecorina, and NcPMO-2 (GenBank no. EAA32426) and NcPMO-3 (GenBank no. EAA33178) from $N$. crassa, was generated using Clustal W (Larkin et al. 2007) and ESPript (Gouet et al. 1999). The homology model of the $C g$ AA9 was constructed from the crystal structure of $T t$ GH61E (PDB code: 3EII). SWISS-MODEL was used as the protein structure modeling server (http://swissmodel.expasy. org/). All atom-contacts and geometry were checked using MolProbity (Chen et al. 2010), and protein structures were illustrated using PyMOL (http://www.pymol.org).

\section{Expression and purification of $\mathrm{CgAA9}$}

The putative signal peptide sequence (Met1-Ala17) of $\mathrm{Cg}$ AA9 was analyzed by neural networks and hidden Markov models (Bendtsen et al. 2004), trained on eukaryotes using the SignalP 3.0 server (http://www.cbs.dtu.dk/services/SignalP-3. $0 /$ ), and excluded from the whole sequence in this study. A codon-optimized CHGG_09805 gene (GenBank accession no. KJ668599) for expression in E. coli was synthesized (Bioneer, Daejeon, Korea), and the synthesized gene was cloned into the pET21a expression vector (Novagen, Darmstadt, Germany). The recombinant gene was transformed into competent $E$. coli BL21 (DE3) cells (Thermo Fisher Scientific, Waltham, MA), the protein expression of CHGG_09805 was induced by adding $0.5 \mathrm{mM}$ isopropyl $\beta$-D-1-thiogalactopyranoside, and the culture was then maintained at $16{ }^{\circ} \mathrm{C}$ for $16 \mathrm{~h}$. Recombinant $\mathrm{CgAA} 9$ was purified from the endogenous proteins of the $E$. coli cells by affinity chromatography using a His-Trap column (GE Healthcare, Little Chalfont, UK). Briefly, cell pellets obtained by centrifugation at $2000 \mathrm{~g}$ for $20 \mathrm{~min}$ were resuspended in equilibrium buffer $(20 \mathrm{mM}$ sodium phosphate and $500 \mathrm{mM} \mathrm{NaCl} ; \mathrm{pH} \mathrm{7.4)} \mathrm{and} \mathrm{disrupted} \mathrm{by} \mathrm{sonication.}$ The sonicated cell suspension was centrifuged at $30,000 \mathrm{~g}$ for $30 \mathrm{~min}$, and the supernatant containing soluble crude enzyme was loaded onto the His-Trap column, which was preequilibrated with the equilibrium buffer. After stepwise washing steps using different concentrations of imidazole buffers (20 mM sodium phosphate and $500 \mathrm{mM} \mathrm{NaCl}$ containing 0 , $10,25,50$, or $75 \mathrm{mM}$ imidazole; $\mathrm{pH} 7.4$ ), the proteins were eluted using elution buffer $(20 \mathrm{mM}$ sodium phosphate, $500 \mathrm{mM} \mathrm{NaCl}$, and $100 \mathrm{mM}$ imidazole; $\mathrm{pH}$ 7.4). The expression and purity of recombinant $\mathrm{CgAA} 9$ were visually analyzed by sodium dodecyl sulfate polyacrylamide gel electrophoresis. The recombinant protein yield from the cell culture was approximately $1.5 \mathrm{mg} / \mathrm{L}$.

\section{DPPH (2,2-diphenyl-1-picrylhydrazyl) assay}

Reducing power was measured by means of DPPH assay. After mixing of $100 \mu \mathrm{L}$ of DPPH radical at $0.2 \mathrm{mM}$ (Sigma-Aldrich, St. Louis, MO) with $100 \mu \mathrm{L}$ of a sample, the mixture was incubated for $30 \mathrm{~min}$. The reducing power of the sample was determined by absorbance at $517 \mathrm{~nm}$. Methanol was used as a blank, and $1 \mathrm{mM}$ of antioxidants such as ascorbic acid, gallate, and reduced glutathione were used as positive controls.

\section{Synergistic hydrolysis by $\mathrm{CgAA9}$ with cellulase}

To determine the synergistic activity of $C g A A 9,1 \%(w / v)$ of Avicel PH 101 (Sigma-Aldrich, St. Louis, MO) was incubated with 1.8 filter paper units (FPU)/g Avicel of Celluclast $1.5 \mathrm{~L}$ (Novozymes, Bagsvaerd, Denmark) in the presence or absence of $1 \mathrm{mg}$ of $\mathrm{CgAA} 9 / \mathrm{g}$ Avicel in $50 \mathrm{mM}$ sodium acetate buffer (pH 5.0) in a total volume of $220 \mu \mathrm{L}$ at $50{ }^{\circ} \mathrm{C}$ for $48 \mathrm{~h}$. Sodium azide $\left(\mathrm{NaN}_{3}\right)$ at $0.02 \%(w / v)$ was added to all the reaction mixtures as an antibiotic. To terminate the enzyme reaction, the reaction mixture was heated at $95{ }^{\circ} \mathrm{C}$ for $5 \mathrm{~min}$, followed by centrifugation at $30,000 \mathrm{~g}$ for $5 \mathrm{~min}$. The supernatant was used for sugar analysis with the 3,5-dinitrosalicylic acid (DNS) assay at $540 \mathrm{~nm}$ using D-glucose as the standard for reducing sugar. For the quantification of glucose and cellobiose, high-performance liquid chromatography (HPLC; Agilent 1100, Agilent Technologies, Waldbronn, Germany) was used with an HPX-87H column (Bio-Rad, Hercules, CA) at $65{ }^{\circ} \mathrm{C}$, with $0.01 \mathrm{~N} \mathrm{H}_{2} \mathrm{SO}_{4}$ at a flow rate of $0.5 \mathrm{~mL} /$ min as the mobile phase. Depending on the experiments, the amounts of Celluclast $1.5 \mathrm{~L}(0.045,0.45,0.9$, and $3.6 \mathrm{FPU} / \mathrm{g}$ Avicel) and CgAA9 (0, 0.9, 1.8, and $3.6 \mathrm{mg} / \mathrm{g}$ Avicel), temperature $\left(20-70^{\circ} \mathrm{C}\right)$, and $\mathrm{pH}(3.0-9.0)$ were varied. Synergism was determined as shown below: synergistic activity of $\mathrm{Cg}$ AA9 $=$ reducing sugar yield produced by cellulase and $C g$ AA9/reducing sugar yield produced by cellulase alone.

\section{Results}

\section{mRNA expression of $\boldsymbol{C g A A 9}$ gene induced by cellulosic substrates}

Induction of the expression of CHGG 09805, a candidate gene for AA9, by cellulosic substrates was examined by reverse transcription-polymerase chain reaction (RT-PCR). The cultivation profiles of $C$. globosum on different carbon sources (glucose, Avicel, and rice straw) showed higher growth rates on cellulosic substrates (i.e., Avicel and rice 
straw) than on glucose (Fig. S1 in the Supplementary Material). The band intensities for the amplified cDNA genes of CHGG_09805 from C. globosum grown on cellulose were higher than that for C. globosum grown on glucose when qualitatively visualized (Fig. 1). The band intensities for the amplified cDNA gene for histone H4.2 (CHGG_10298), which was used as the housekeeping gene, showed no significant differences regardless of whether C. globosum was grown on cellulose or glucose (Fig. 1). These results demonstrate that the messenger RNA (mRNA) expression of CHGG_09805 was strongly induced during growth on cellulosic substrates. This suggests that the protein encoded in CHGG_09805 is probably involved in cellulose degradation in C. globosum.

\section{Sequence alignment and homology modeling}

To understand the potential function of $\mathrm{CgAA} 9$ as the general activity of AA9, sequence alignment and homology modeling were performed. From the sequence alignment using other AA9s with known structures, the structure of $C g A A 9$ exhibited high similarity to those known AA9s compared here, especially to $T t \mathrm{GH} 61 \mathrm{E}$ (sequence identity of $61 \%$ ). In addition, amino acid residues that are reported to be highly conserved in other AA9s (His1, His69, and Tyr154) were also contained in $\mathrm{CgAA} 9$ (Fig. 2a). These conserved residues are divalent metal-binding residues that are known to be important in enzyme activity (Harris et al. 2010; Karkehabadi et al. 2008; Li et al. 2012; Quinlan et al. 2011; Wu et al. 2013).

Homology modeling of $C g \mathrm{AA} 9$ was performed using $T t$ GH61E as the template. The model structure of $C g A A 9$ was revealed to possess an immunoglobulin-like $\beta$-sandwich fold and the conserved metal-binding sites (His1, His69, and Tyr154) were observed on the surface. In addition, the putative substrate-binding or recognition sites (Tyr22, Tyr193, and Tyr194 in CgAA9) that are linearly positioned with the metalbinding motif were observed (Fig. 2b). Next, the metalbinding motif and the putative substrate-binding residues of CgAA9 were superimposed with those of other AA9 homologs (Fig. 2c). The three metal-binding sites and Tyr193 in CgAA9 were structurally conserved among AA9 homologs, but Tyr194 in CgAA9 was conserved only with Tyr192 in TtGH61E. Meanwhile, Tyr22 in CgAA9 was not observed with $T t \mathrm{GH} 61 \mathrm{E}$, but this residue is considered functionally equivalent to Tyr24 in TaGH61A, Tyr23 in HjGH61B, Tyr25 in NcPMO-2, or Tyr20 (or Tyr24) in NcPMO-3 as the substrate-binding site.

\section{Synergism of $C g \mathrm{AA} 9$ in cellulose hydrolysis by cellulase}

To determine the synergistic activity of recombinant $C g \mathrm{AA} 9$ with cellulase, $C g$ AA9 was incubated with Celluclast $1.5 \mathrm{~L}$ and Avicel for cellulose hydrolysis. The synergism of $C g A A 9$

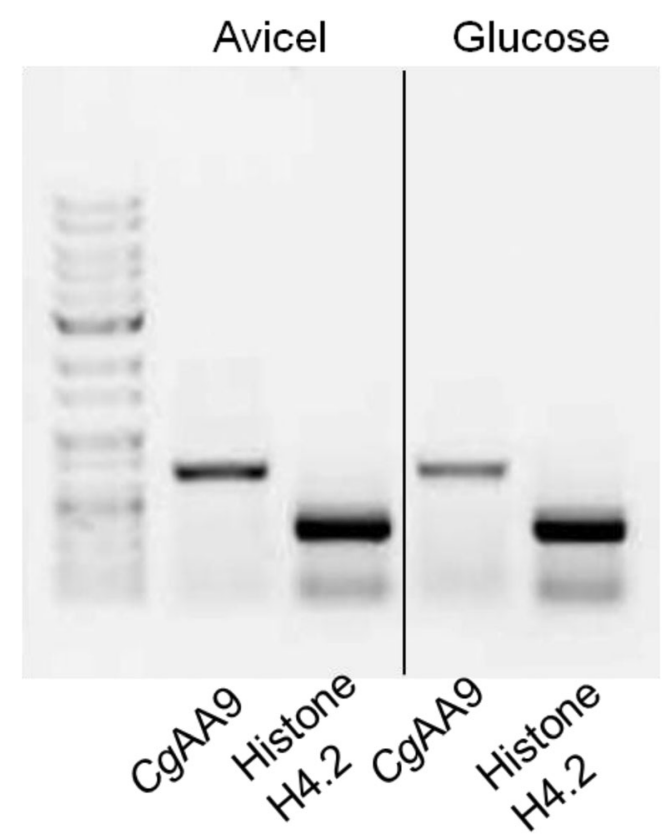

Fig. 1 Upregulation of the CHGG_09805 gene induced by cellulosic substrates. Lanes 1 and 2 indicate the amplified cDNA genes for CHGG_09805 and CHGG_10298 (histone H4.2), respectively, obtained from C. globosum grown on Avicel. Lanes 3 and 4 indicate the amplified cDNA genes for CHGG_09805 and CHGG_10298 (histone H4.2), respectively, obtained from C. globosum grown on glucose

was measured without supplying any external electron donors throughout the experiments. This is because $\mathrm{NaN}_{3}(0.02 \%, w /$ $v$ ) added as an antibiotic to the enzymatic reaction mixture was shown to act as a reducing cofactor for $C g A A 9$ (Figs. 3 and S2 in the Supplementary Material).

In the control experiment involving $C g A A 9$ alone with Avicel, CgAA9 did not yield sugar products detectable by the DNS reagent. However, when $C g A A 9$ was added into the reaction mixture containing Celluclast $1.5 \mathrm{~L}$ and Avicel, the reducing sugar yield was significantly greater than that without $C g$ AA9 (Fig. 4). The synergism of $C g A A 9$ was demonstrated at two different loading concentrations ( 0.6 and 1.2 FPU/g cellulose) of Celluclast $1.5 \mathrm{~L}$ at all reaction times. To determine the feasibility of the actual application of accessory proteins, the cellulose hydrolysis level and cellulase loading level at which the synergism of the accessory protein is exhibited should be taken into account (Rudolf et al. 2008; Yang et al. 2006). In this study, synergism by $C g A A 9$ was observed when the cellulose hydrolysis yield was $\sim 20 \%$ of the theoretical maximum using 1.2 FPU of Celluclast $1.5 \mathrm{~L} / \mathrm{g}$ Avicel. These levels of cellulose hydrolysis yield in this study are comparable to those commonly used for testing enzymatic digestibility or the simultaneous saccharification and fermentation (SSF) of lignocellulose (Rudolf et al. 2008; Yang et al. 2006). Since the major products of cellulose hydrolysis by Celluclast $1.5 \mathrm{~L}$ are glucose and cellobiose, the amounts of glucose and cellobiose from the hydrolysis of Avicel with 


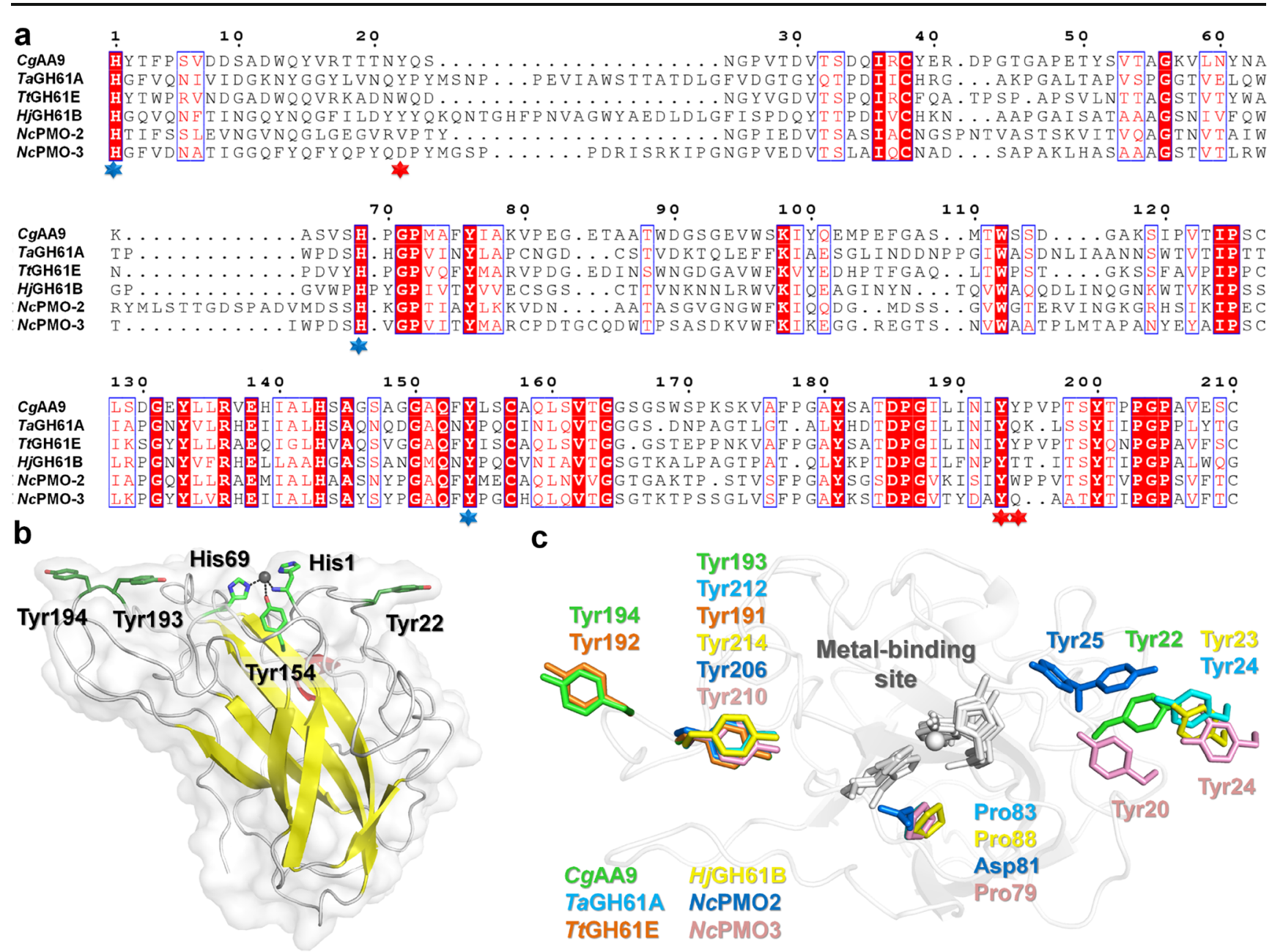

Fig. 2 Sequence analysis and structural modeling of $C g A A 9$. a Sequence alignment of CgAA9 (accession no.: EAQ83401) with other AA9s including $T a$ GH61A (ACS05720), $T t$ GH61E (ACE10234), $\mathrm{HjGH61B}$ (AY281372), NcPMO-2 (EAA32426), and $N c$ PMO-3 (EAA33178). The conserved residues are boxed in red, and the homologous residues are indicated by unfilled boxes with red letters. Residues involved in metal binding and putative substrate binding are marked with blue and red asterisks, respectively. The signal peptide sequence (Met1-Ala17) of CgAA9 is not shown in the figure. b

Celluclast $1.5 \mathrm{~L}$ with or without $C g A A 9$ were quantified in this study (Fig. S3 in the Supplementary Material). The addition of CgAA9 to the mixture of Celluclast $1.5 \mathrm{~L}$ and Avicel led to 1.3-fold and 1.2-fold increases in both glucose and cellobiose after $48 \mathrm{~h}$, respectively (Fig. S3 in the Supplementary Material), compared to the control without $C g A A 9$.

\section{Effects of loading amounts of $\mathrm{CgAA9}$ and cellulase on synergism by $\mathrm{CgAA9}$}

The mass ratio of an accessory protein and cellulase in their synergism is one of the key factors determining the economic feasibility of the accessory protein (Kim et al. 2009). The effects of the loading amounts of $C g A A 9$ and cellulase on synergism in cellulose hydrolysis were investigated in this study (Fig. 5).
Cartoon representation of the structural model of $C g A A 9$. The functionally important residues are shown as sticks. The highly conserved metal-binding motifs (His1, His 69, and Tyr154) are shown as sticks in green. Putative substrate-binding sites (Tyr22, Tyr193, and Tyr194) are shown as sticks in forest. $\mathbf{c}$ The superimposition of putative substrate-binding site of AA9 homologs. $C g A A 9, T a$ GH61A (PDB code: 2YET), TtGH61E (3EII), HjGH61B (2VTC), NcPMO2 (4EIR), and NcPMO3 (4EIS) are indicated by green, teal, orange, yellow, blue, and pink, respectively. The metal-binding residues are indicated by grey sticks

When $C g$ AA9 was added at $0.9 \mathrm{mg} / \mathrm{g}$ Avicel, significantly higher reducing sugar yields $(1.3,4.5,8.3$, and $18 \%$ of the theoretical maximum of glucose, respectively; Fig. 5) were observed with all loadings of Celluclast $1.5 \mathrm{~L}(0.045,0.45,0.9$, and $3.6 \mathrm{FPU} / \mathrm{g}$ Avicel) $(p<0.05)$ than in controls without $C g \mathrm{AA} 9$. Overall, the highest extent of synergism (approximately 1.7-fold) was obtained with 0.45 or $0.9 \mathrm{FPU}$ of Celluclast $1.5 \mathrm{~L} / \mathrm{g}$ Avicel, regardless of the loading amount of $C g \mathrm{AA} 9$ (Fig. 5b, c). When the Celluclast 1.5 L loading amount was $0.045 \mathrm{FPU} / \mathrm{g}$ Avicel, synergism increased with an increase in CgAA9 loading (Fig. 5a). When the Celluclast $1.5 \mathrm{~L}$ loading was 0.45 or $0.9 \mathrm{FPU} / \mathrm{g}$ Avicel, the extent of synergism was not affected by varying the loading of CgAA9 ( $p>0.05$ ) (Fig. 5b, c). On the contrary, when the cellulase loading was $3.6 \mathrm{FPU} / \mathrm{g}$ Avicel, at 1.8 and $3.6 \mathrm{mg} / \mathrm{g}$ Avicel, reducing sugar yields did not increase 


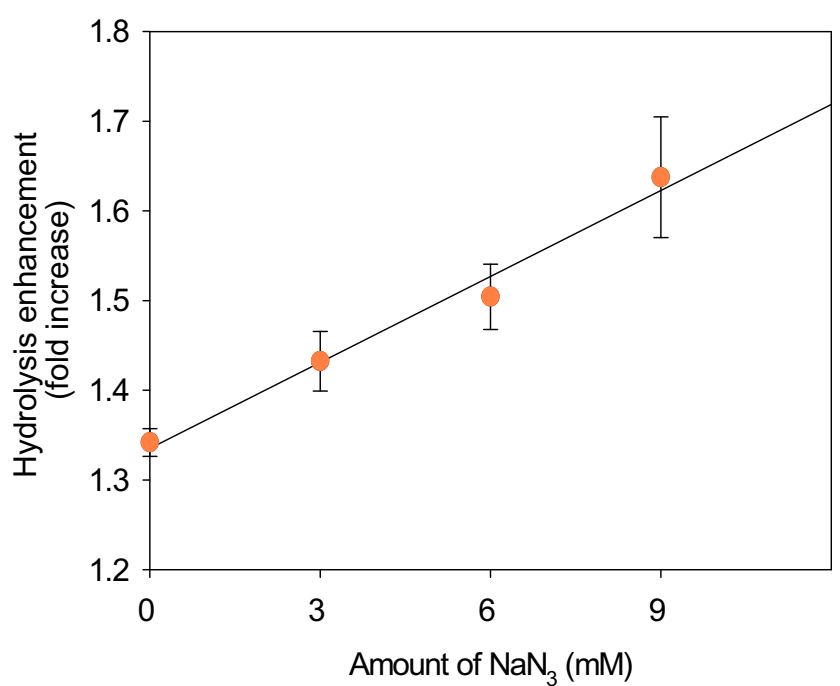

Fig. 3 Effect of $\mathrm{NaN}_{3}$ on the synergistic activity of $\mathrm{CgAA} 9$ with cellulase in the hydrolysis of cellulose. Avicel $(1 \%, w / v)$ was hydrolyzed by Celluclast $1.5 \mathrm{~L}$ (0.9 FPU/g Avicel) and/or CgAA9 $\left(1.8 \mathrm{mg} / \mathrm{g}\right.$ Avicel) for $48 \mathrm{~h}$ at $50{ }^{\circ} \mathrm{C}$ in $50 \mathrm{mM}$ sodium acetate buffer ( $\mathrm{pH}$ 5.0). The amounts of $\mathrm{NaN}_{3}$ tested were $0,3,6$, and $9 \mathrm{mM}$. Synergistic activity was represented as fold increase of reducing sugar generated from Avicel. Data are means \pm standard errors

as much as at $0.9 \mathrm{mg} / \mathrm{g}$ Avicel. This is possibly because at higher cellulase (i.e., 3.6 FPU/g cellulose) and higher AA9 loadings (i.e., 1.8 and $3.6 \mathrm{mg} / \mathrm{g}$ cellulose), cellulase and $\mathrm{CgAA} 9 \mathrm{might}$ have competed for cellulose as the substrate. Such phenomenon was also observed in other synergistic proteins (Kim et al. 2009).

\section{Effect of temperature and $\mathrm{pH}$ on synergism by $\mathrm{CgAA9}$}

To study the effect of temperature on the synergistic activity of CgAA9, cellulose hydrolysis experiments were performed at various temperatures ranging from 20 to $70{ }^{\circ} \mathrm{C}$ (Fig. 6a). The

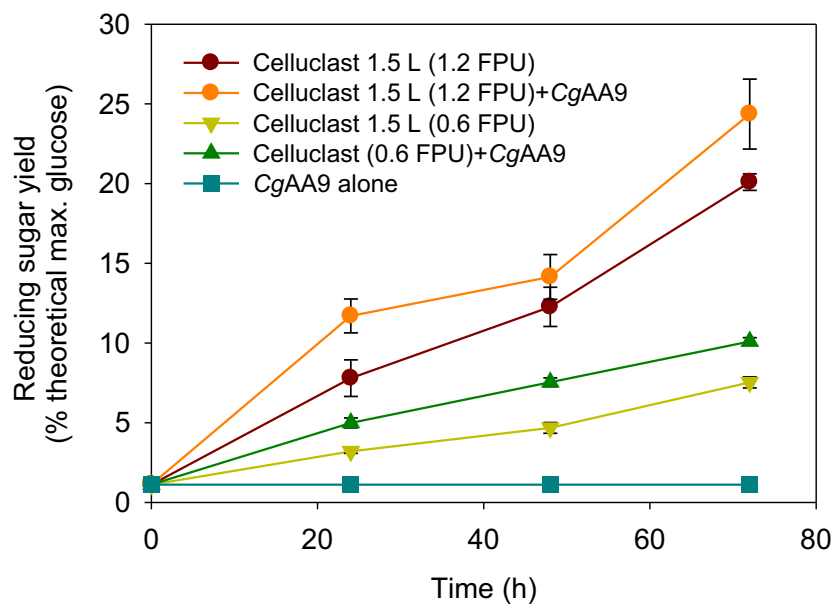

Fig. 4 Time course of synergistic activity of $C g A A 9$ with cellulase in the hydrolysis of cellulose. Avicel $(1 \%, w / v)$ was hydrolyzed by Celluclast $1.5 \mathrm{~L}$ (0.6 and 1.2 FPU/g Avicel) and/or $C g A A 9(1.8 \mathrm{mg} / \mathrm{g}$ Avicel $)$ in the presence of $0.02 \%(w / v)$ of $\mathrm{NaN}_{3}$ for $0,24,48$, and $72 \mathrm{~h}$ at $50{ }^{\circ} \mathrm{C}$ in $50 \mathrm{mM}$ sodium acetate buffer ( $\mathrm{pH}$ 5.0). Data are means \pm standard errors production of reducing sugar from Avicel by Celluclast $1.5 \mathrm{~L}$ alone was strongly temperature-dependent, and the highest activity was exhibited at $50^{\circ} \mathrm{C}$, which is the optimal temperature of Celluclast $1.5 \mathrm{~L}$. When $C g \mathrm{AA} 9$ was incubated with cellulase, the synergistic activity of $\mathrm{CgAA} 9$ was observed at $50{ }^{\circ} \mathrm{C}$. At other temperatures, the synergistic activity of $\mathrm{Cg}$ AA9 was negligible or not observed. These results show that the synergism of $\mathrm{CgAA} 9$ is highly dependent on the optimal temperature of cellulase. For industrial application, $C g A A 9$ is not appropriate for typical SSF, in which saccharification and fermentation processes are performed together at $38^{\circ} \mathrm{C}$. Instead, $C g$ AA9 could possibly be utilized in the hydrolysis step of the separate hydrolysis and fermentation (SHF) process because the typical temperature for hydrolysis is $50^{\circ} \mathrm{C}$.

To investigate the effect of $\mathrm{pH}$ on the synergism of $\mathrm{CgAA} 9$ and cellulase, cellulose hydrolysis experiments were performed at different $\mathrm{pH}$ values ranging from 3.0 to 9.0 (Fig. 6b). Similar to the effect of temperature on the activity of cellulase alone, the activity of cellulase alone was highly dependent on $\mathrm{pH}$; the maximal reducing sugar yield of Celluclast $1.5 \mathrm{~L}$ was seen at $\mathrm{pH}$ 5.0. When $C g A A 9$ was added to the hydrolysis reaction mixture, synergism was observed at pH 4.0 (1.4-fold), 5.0 (1.3-fold), and 6.0 (1.3-fold), whereas no significant synergism was seen at $\mathrm{pH} 3.0,7.0,8.0$, and 9.0 $(p>0.05)$. The synergistic activity of $C g A A 9$ was exhibited only at the $\mathrm{pH}$ where the activity of Celluclast $1.5 \mathrm{~L}$ alone was adequately high. From these results, temperature and $\mathrm{pH}$ were found to be the key factors to be considered in the industrial utilization of $C g \mathrm{AA} 9$ as synergistic protein.

\section{Synergistic or stabilizing effect of $\mathrm{CgAA9}$}

To determine whether the increase in cellulose hydrolysis yield by $C g A A 9$ was due to a synergistic or stabilizing effect, bovine serum albumin (BSA) was selected as an additive control protein due to its extensive use in the stabilization of enzymes (Brethauer et al. 2011; Hu et al. 2011). In this study, comparing the effects of BSA and CgAA9, the increase in cellulose hydrolysis yield by $\mathrm{CgAA} 9$ was significantly greater (e.g., 1.7-fold) than that by the same molar mass of BSA (e.g., 1.3 -fold) $(p<0.05)$ (Fig. 7).

\section{Discussion}

AA9-encoding genes are distributed throughout a variety of cellulytic fungi, probably due to their essential role in cellulose degradation (Martinez et al. 2009; Phillips et al. 2011b; Tian et al. 2009; Vanden Wymelenberg et al. 2009). Especially, C. globosum, the soil fungus used as the genetic source of AA9 in this study, possesses more than forty-four AA9encoding genes (Lakshmikant and Mathur 1990; Longoni et al. 2012), and CHGG_09805 (CgAA9) is one of them. In 

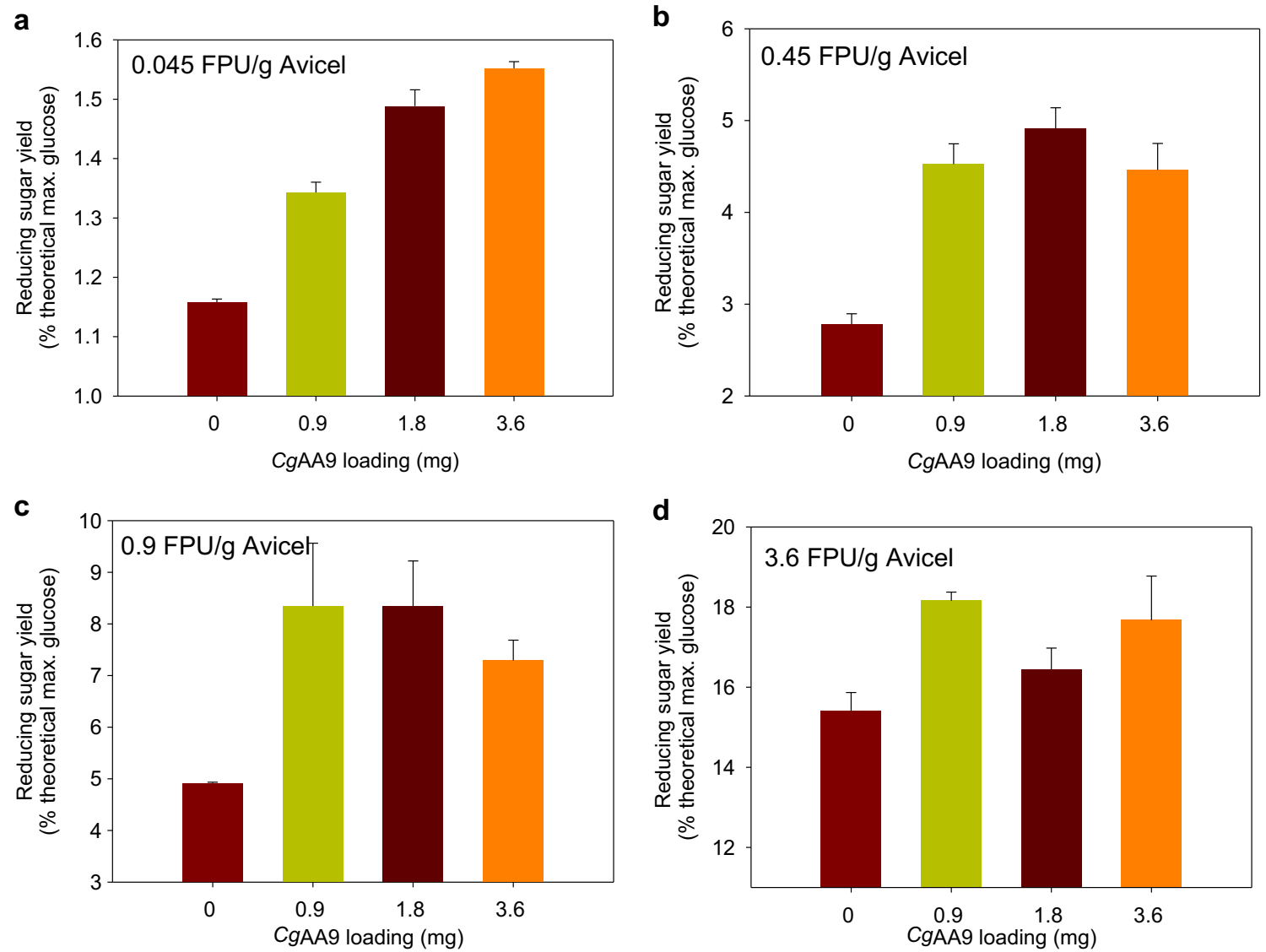

Fig. 5 Effect of the loading of $C g A A 9$ and cellulase on their synergism in the hydrolysis of cellulose. Avicel $(1 \%, w / v)$ was hydrolyzed using four different concentrations of Celluclast $1.5 \mathrm{~L}$ : a 0.045 , b 0.45 , c 0.9 , and d $3.6 \mathrm{FPU} / \mathrm{g}$ Avicel with or without four different concentrations of

this study, mRNA expression of CHGG_09805 was induced during growth on cellulosic compounds, implying its potential involvement in cellulose hydrolysis. Moreover, sequence

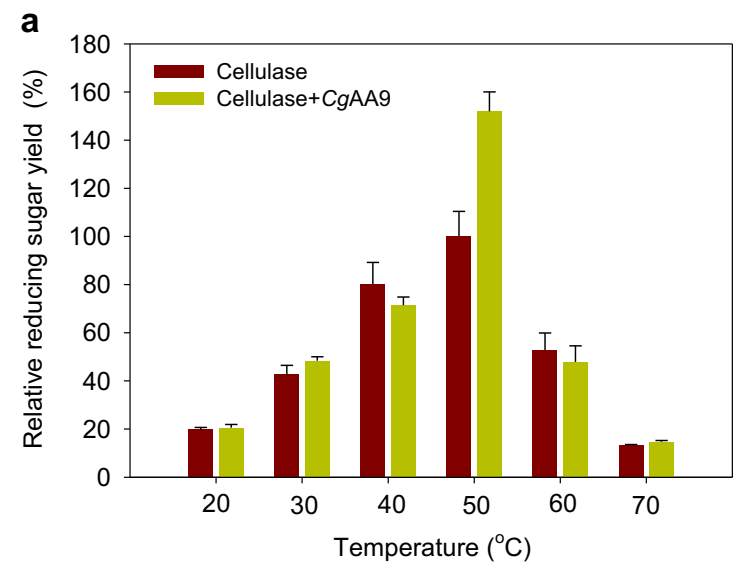

Fig. 6 Effect of temperature and $\mathrm{pH}$ on the synergism of $\mathrm{CgAA} 9$ and cellulase in the hydrolysis of cellulose. a Avicel $(1 \%, w / v)$ was hydrolyzed by $0.9 \mathrm{FPU}$ of Celluclast $1.5 \mathrm{~L} / \mathrm{g}$ Avicel with or without $1.8 \mathrm{mg}$ of $C g \mathrm{AA} 9 / \mathrm{g}$ Avicel for $48 \mathrm{~h}$ at different temperatures of 20 $70{ }^{\circ} \mathrm{C}$ in $50 \mathrm{mM}$ sodium acetate buffer $(\mathrm{pH} 5.0)$. b Avicel $(1 \%, w / v)$ was hydrolyzed by $0.9 \mathrm{FPU}$ of Celluclast $1.5 \mathrm{~L} / \mathrm{g}$ Avicel with or without

CgAA9 at $0,0.9,1.8$, and $3.6 \mathrm{mg} / \mathrm{g}$ Avicel in the presence of $0.02 \%(w / v)$ of $\mathrm{NaN}_{3}$ for $48 \mathrm{~h}$ at $50{ }^{\circ} \mathrm{C}$ in $50 \mathrm{mM}$ sodium acetate buffer (pH 5.0). Data are means \pm standard errors

analysis and structural homology modeling of CHGG_09805 revealed its potential synergistic activity as an AA9. Specifically, CgAA9 shares conserved divalent metal-binding

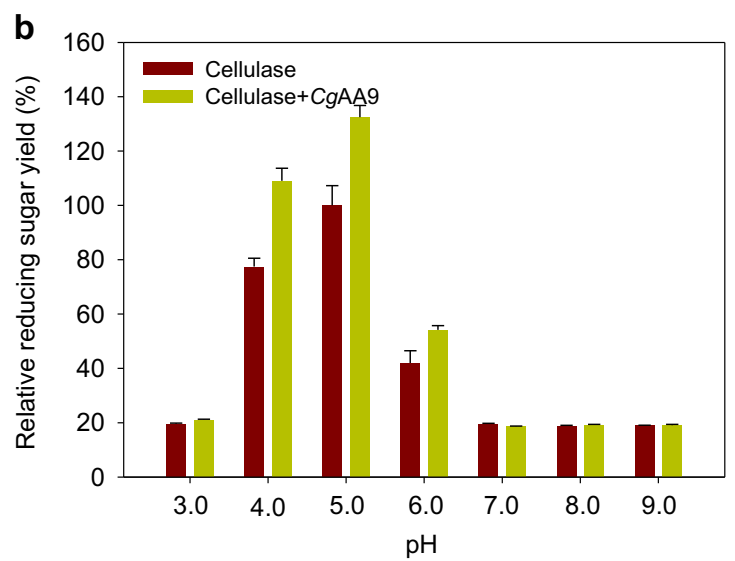

$1.8 \mathrm{mg}$ of $\mathrm{CgAA} 9 / \mathrm{g}$ Avicel for $48 \mathrm{~h}$ at $\mathrm{pH} 3.0$ to 8.0 at $50{ }^{\circ} \mathrm{C} ; 50 \mathrm{mM}$ sodium citrate buffer (for $\mathrm{pH} 3.0$ to 6.0 ), $50 \mathrm{mM}$ potassium phosphate buffer (for $\mathrm{pH} 7.0$ ), $50 \mathrm{mM}$ Tris- $\mathrm{HCl}$ buffer (for $\mathrm{pH} 8.0$ ), and $50 \mathrm{mM}$ glycine- $\mathrm{NaOH}$ for $(\mathrm{pH} 9.0)$ were used for different $\mathrm{pH}$ values. Experiments were conducted in the presence of $0.02 \%(w / v)$ of $\mathrm{NaN}_{3}$. Data are means \pm standard errors 


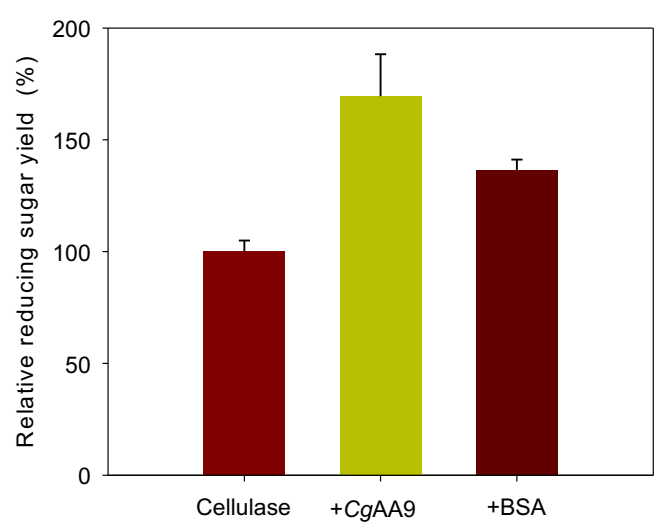

Fig. 7 Comparison of the synergistic activities of $C g A A 9$ and BSA. Avicel $(1 \%, w / v)$ was hydrolyzed by $0.9 \mathrm{FPU}$ of Celluclast $1.5 \mathrm{~L} / \mathrm{g}$ Avicel with or without $1.8 \mathrm{mg}$ of $\mathrm{CgAA} 9$ or $4.8 \mathrm{mg}$ of BSA/g Avicel in the presence of $0.02 \%(w / v)$ of $\mathrm{NaN}_{3}$ for $48 \mathrm{~h}$ at $50{ }^{\circ} \mathrm{C}$ in $50 \mathrm{mM}$ sodium acetate buffer ( $\mathrm{pH} 5.0$ ); equal molar masses of $C g A A 9$ and BSA were used. Data are means \pm standard errors

residues with other AA9s that are known to be important in its activity (His1, His69, and Tyr154) (Harris et al. 2010; Karkehabadi et al. 2008; Li et al. 2012; Quinlan et al. 2011; Wu et al. 2013). The homology modeling of CgAA9 presented here suggests that these residues are plausible to exist on the surface of $C g A A 9$ and well superimposed on the corresponding residues of known structures of other AA9s (Harris et al. 2010; Karkehabadi et al. 2008; Li et al. 2012; Quinlan et al. 2011; Wu et al. 2013).

In this study, CgAA9 expressed in E. coli showed synergistic activity in the hydrolysis of pure cellulose (Avicel) without adding an external reducing cofactor. This is because the reaction mixture for $\mathrm{CgAA} 9$ possessed reducing power as revealed by the DPPH assay (Fig. S2 in the Supplementary Material). Of the components contained in the reaction mixture, $\mathrm{NaN}_{3}$ was found to be a major contributor to the overall reducing power of reaction mixture (Fig. 3). The extent of synergism by $\mathrm{CgAA} 9$ increased with increasing the concentration of $\mathrm{NaN}_{3}$ from 0 to
$9 \mathrm{mM}$. In several previous studies, AA9s showed no or little synergistic activity on pure cellulose without an external electron donor (Dimarogona et al. 2012; Cannella et al. 2012; Harris et al. 2010). However, when using pretreated lignocellulose, an external electron donor was not required since lignin in pretreated lignocellulose reducing power for AA9 (Dimarogona et al. 2012; Hu et al. 2014). Taken together, the requirement of an electron donor for AA9 was confirmed in this study. However, reaction products including native and oxidized sugars were not detected by the analysis of matrixassisted laser desorption/ionization tandem time of flight/mass spectrometer (MALDI-TOF/TOF MS) when CgAA9 alone without cellulase was incubated on cellulose (data not shown). No detection of reaction products by $C g \mathrm{AA} 9$ was possibly due to the low enzymatic activity of $C g \mathrm{AA} 9$.

In this study, a fungal AA9 was functionally expressed in a bacterial host. Previously, post-translational modifications including glycosylation and methylation were observed in some AA9s. Specifically, methylated His1 was observed in $\mathrm{Ta}$ GH61A (Quinlan et al. 2011), and PMOs from N. crassa (PMO-2 and PMO-3) were revealed to contain the sites of $\mathrm{N}$-glycosylation ( $\mathrm{Li}$ et al. 2012). However, the type and pattern of post-translational modifications in AA9s are random and diverse, and their functional significance on cellulose hydrolysis still remains elusive ( $\mathrm{Li}$ et al. 2012). Main functions of AA9s such as synergistic activity and reducing cofactordependent activity were observed in $C g A A 9$ which was expressed in $E$. coli lacking post-translational modification. This result implies that bacterial expression of fungal AA9 is able to function even without post-translation modifications. Furthermore, a recent study reported that methylation of His 1 had a minor effect on AA9's activity (Kim et al. 2014). Still, the exact functional significance of methylation or glycosylation on AA9 requires further study. Although our fungal $\mathrm{Cg}$ AA9 expressed in E. coli functioned as an AA9, it cannot be ruled out that $C g A A 9$ could have shown higher synergism

Table 1 Comparison of the synergistic activity of $C g$ AA9 with Celluclast $1.5 \mathrm{~L}$ on crystalline cellulose with those of other synergistic proteins such as AA9s, AA10, and bacterial expansins

\begin{tabular}{llllll}
\hline & $\begin{array}{l}\text { Extent of } \\
\text { synergism (fold) }\end{array}$ & $\begin{array}{l}\text { Synergistic protein } \\
\text { loading (mg/g cellulose) }\end{array}$ & $\begin{array}{l}\text { Hydrolysis yield } \\
\text { without synergistic } \\
\text { protein (\% theoretical max.) }\end{array}$ & $\begin{array}{l}\text { Hydrolysis yield } \\
\text { with synergistic } \\
\text { protein (\% theoretical max.) }\end{array}$ \\
\hline $\begin{array}{l}\text { CgAA9 } \\
\text { (this study) }\end{array}$ & 1.2 & 0.9 & 15.4 & 18.2 & 8.3 \\
$\begin{array}{l}P c \text { GH61D } \\
\text { (Westereng et al. 2011) }\end{array}$ & 1.7 & 0.9 & 4.9 & 17.3 & Avicel \\
$\begin{array}{l}\text { CBM33 } \\
\text { (Forsberg et al. 2011) }\end{array}$ & 1.3 & 5.6 & 13.6 & 9.1 & Avicel \\
$\begin{array}{l}\text { BsEXLX1 } \\
\text { (Kim et al. 2009) }\end{array}$ & 5.7 & 4.0 & 3.6 & 1.8 & Avicel \\
$\begin{array}{l}\text { HcEXLX2 } \\
(\text { Lee et al. 2010) }\end{array}$ & 5.1 & 0.3 & 0.3 & 3.6 & Filter paper \\
\hline
\end{tabular}


with post-translational modifications. It would be interesting to compare the activities of AA9s expressed in either prokaryotic or eukaryotic system in further study.

When determining the feasibility of the actual application of synergistic proteins, key determinants are extent of synergism, synergistic protein loading and hydrolysis yield (Rudolf et al. 2008; Yang et al. 2006). If the addition of a small amount of an accessory protein brings about a substantial increase in cellulase activity, the loading amount of cellulase can be reduced to lower the enzyme cost in the industrial process. In addition, the high yield of hydrolysis at which the synergism of the accessory protein is exhibited is required for the industrial conversion of cellulose. In this regard, synergistic performance of $C g A A 9$ was compared with those of other nonhydrolytic accessory proteins, which were selected based on their synergistic activity on pure cellulose (Table 1) (Dimarogona et al. 2012; Forsberg et al. 2011; Kim et al. 2009; Lee et al. 2010; Westereng et al. 2011). At a high hydrolysis yield when $0.9 \mathrm{mg}$ of $C g A A 9$ was incubated with 3.6 FPU/g Avicel, the synergistic activity of $C g A A 9$ (1.2-fold) was comparable to that of PcGH61D (1.3-fold) at a similar yield of cellulose hydrolysis (17-19\%). However, the protein loading of $C g A A 9$ required to achieve a similar extent of synergism was approximately 6.2 times lower than that for PcGH61D in our study (Westereng et al. 2011).

For the comparison with synergistic proteins other than AA9, $0.9 \mathrm{mg}$ of $C g A$ A9 with 0.9 FPU of Celluclast $1.5 \mathrm{~L} / \mathrm{g}$ Avicel was chosen, at which the highest synergistic activity (1.7-fold) was shown in this study. When compared with that by CBM33, the synergism by a 4.4-fold lower loading amount of $C g$ AA9 was lower only by 1.5 -fold than that of CBM33 to achieve a similar yield of cellulose hydrolysis (8-10\%) (Forsberg et al. 2011). When the synergism by $C g A A 9$ was compared to those of bacterial expansins such as BsEXLX1 and $H c$ EXLX2, these two bacterial expansins exhibited synergism only at much lower loadings of Celluclast $1.5 \mathrm{~L}$ than did CgAA9 in our study (Kim et al. 2009; Lee et al. 2010). Therefore, the synergistic activities of $B s \mathrm{EXLX} 1$ and $\mathrm{Hc}$ EXLX2 are not industrially feasible because their synergism is seen at a low hydrolysis yield of cellulose. Overall, the synergism by $C g A A 9$ in this study is more practically applicable than those of other non-hydrolytic accessory proteins selected here. This is because the synergism is seen at lower loading levels of CgAA9 or at a higher hydrolysis level of cellulose than in the case of other accessory proteins.

The reducing sugar yield enhanced by $C g A A 9$ was significantly higher than that by BSA. This implies that the increased reducing sugar by $C g A A 9$ is more than a stabilizing effect and is rather a synergistic effect. BSA is often added to enzyme reaction mixtures as a stabilizing agent due to its ability to reduce the deactivation of cellulases that occurs at the air-liquid interface (Brethauer et al. 2011; Hu et al. 2011; Kim et al. 1982). Likewise, the enhancing effect by BSA observed in this study is considered a stabilizing effect rather than a synergistic effect causing alterations in cellulose structure. Indeed, there is no report of structural disruption of cellulose by BSA (Brethauer et al. 2011; Hu et al. 2011). By contrast, the effect of $C g A A 9$ on cellulose hydrolysis in the present study may be due to the direct alteration of cellulose, probably caused by the PMO activity of CgAA9. In conclusion, the first expression of a fungal AA9 in a bacterial host and the optimization for its synergism without the requirement for external electron donors will facilitate the development of synergistic proteins for the industrial application.

Acknowledgments This work was supported by grants from the National Research Foundation of Korea (2013M1A2A2072597) and the Advanced Biomass R\&D Center of Korea (2011-0031353), both funded by the Korean Government (MSIP). The financial support by School of Life Sciences and Biotechnology for BK21 PLUS, Korea University, the facility support at Korea University Food Safety Hall for the Institute of Biomedical Science and Food Safety, and a Korea University grant support for I.-G. Choi are also acknowledged.

Conflict of interest The authors declare that they have no competing interests.

Open Access This article is distributed under the terms of the Creative Commons Attribution 4.0 International License (http:// creativecommons.org/licenses/by/4.0/), which permits unrestricted use, distribution, and reproduction in any medium, provided you give appropriate credit to the original author(s) and the source, provide a link to the Creative Commons license, and indicate if changes were made.

\section{References}

Arantes V, Saddler JN (2010) Access to cellulose limits the efficiency of enzymatic hydrolysis: the role of amorphogenesis. Biotechnol Biofuels 3:4

Beeson WT, Phillips CM, Cate JHD, Marletta MA (2012) Oxidative cleavage of cellulose by fungal copper-dependent polysaccharide monooxygenases. J Am Chem Soc 134:890-892

Bendtsen JD, Nielsen H, von Heijne G, Brunak S (2004) Improved prediction of signal peptides: signalP 3.0. J Mol Biol 340:783-795

Bey M, Zhou S, Poidevin L, Henrissat B, Coutinho PM, Berrin J-G, Sigoillot J-C (2013) Cello-oligosaccharide oxidation reveals differences between two lytic polysaccharide monooxygenases (family GH61) from Podospora anserina. Appl Environ Microbiol 79:488496

Brethauer S, Studer MH, Yang B, Wyman CE (2011) The effect of bovine serum albumin on batch and continuous enzymatic cellulose hydrolysis mixed by stirring or shaking. Bioresour Technol 102:6295-6298

Cannella D, Hsieh CW, Felby C, Jørgensen H (2012) Production and effect of aldonic acids during enzymatic hydrolysis of lignocellulose at high dry matter content. Biotechnol Biofuels 5:26

Chen VB, Arendall WB 3rd, Head JJ, Keedy DA, Immormino RM, Kapral GJ, Murray LW, Richardson JS, Richardson DC (2010) Molprobity: all-atom structure validation for macromolecular crystallography. Acta Crystallogr D Biol Crystallogr 66:12-21 
Dimarogona M, Topakas E, Olsson L, Christakopoulos P (2012) Lignin boosts the cellulase performance of a GH-61 enzyme from Sporotrichum thermophile. Bioresour Technol 110:480-487

Din N, Gilkes NR, Tekant B, Miller RC, Warren AJ, Kilburn DG (1991) Non-hydrolytic disruption of cellulose fibers by the binding domain of a bacterial cellulase. Nat Biotechnol 9:1096-1099

Din N, Damude HG, Gilkes NR, Miller RC, Warren RAJ, Kilburn DG (1994) $C_{1}-C_{x}$ revisited - intramolecular synergism in a cellulase. Proc Natl Acad Sci U S A 91:11383-11387

Forsberg Z, Vaaje-Kolstad G, Westereng B, Bunaes AC, Stenstrom Y, MacKenzie A, Sørlie M, Horn SJ, Eijsink VGH (2011) Cleavage of cellulose by a CBM33 protein. Protein Sci 20:1479-1483

Gilligan W, Reese ET (1954) Evidence for multiple components in microbial cellulases. Can J Microbiol 1:90-107

Gouet P, Courcelle E, Stuart DI, Metoz F (1999) ESPript: analysis of multiple sequence alignments in postscript. Bioinformatics 15:305-308

Harris PV, Welner D, McFarland KC, Re E, Poulsen JC-N, Brown K, Salbo R, Ding HS, Vlasenko E, Merino S, Xu F, Cherry J, Larsen S, Lo Leggio L (2010) Stimulation of lignocellulosic biomass hydrolysis by proteins of glycoside hydrolase family 61: structure and function of a large, enigmatic family. Biochemistry 49:3305-3316

Hu J, Arantes V, Saddler JN (2011) The enhancement of enzymatic hydrolysis of lignocellulosic substrates by the addition of accessory enzymes such as xylanase: is it an additive or synergistic effect? Biotechnol Biofuels 4:36

Hu J, Arantes V, Pribowo A, Gourlay K, Saddler JN (2014) Substrate factors that influence the synergistic interaction of AA9 and cellulases during the enzymatic hydrolysis of biomass. Energy Environ Sci 7:2308-2315

Karkehabadi S, Hansson H, Kim S, Piens K, Mitchinson C, Sandgren M (2008) The first structure of a glycoside hydrolase family $61 \mathrm{mem}$ ber, Cel61B from Hypocrea jecorina, at 1.6 angstrom resolution. J Mol Biol 383:144-154

Kim MH, Lee SB, Ryu DDY, Reese ET (1982) Surface deactivation of cellulase and its prevention. Enzyme Microb Technol 4:99-103

Kim ES, Lee HJ, Bang W-G, Choi I-G, Kim KH (2009) Functional characterization of a bacterial expansin from Bacillus subtilis for enhanced enzymatic hydrolysis of cellulose. Biotechnol Bioeng 102:1342-1353

Kim S, Ståhlberg J, Sandgren M, Paton RS, Beckham GT (2014) Quantum mechanical calculations suggest that lytic polysaccharide monooxygenases use a copper-oxyl, oxygen-rebound mechanism. Proc Natl Acad Sci U S A 111:149-154

Lakshmikant K, Mathur SN (1990) Cellulolytic activities of Chaetomium globosum on different cellulosic substrates. World J Microbiol Biotechnol 6:23-26

Langston JA, Shaghasi T, Abbate E, Xu F, Vlasenko E, Sweeney MD (2011) Oxidoreductive cellulose depolymerization by the enzymes cellobiose dehydrogenase and glycoside hydrolase 61. Appl Environ Microbiol 77:7007-7015

Larkin MA, Blackshields G, Brown NP, Chenna R, McGettigan PA, McWilliam H, Valentin F, Wallace IM, Wilm A, Lopez R, Thompson JD, Gibson TJ, Higgins DG (2007) Clustal W and Clustal X version 2.0. Bioinformatics 23:2947-2948

Lee HJ, Lee S, Ko HJ, Kim KH, Choi I-G (2010) An expansin-like protein from Hahella chejuensis binds cellulose and enhances cellulase activity. Mol Cells 29:379-385

Levasseur A, Drula E, Lombard V, Coutinho PM, Henrissat B (2013) Expansion of the enzymatic repertoire of the CAZy database to integrate auxiliary redox enzymes. Biotechnol Biofuels 6:41

Li X, Beeson WT, Phillips CM, Marletta MA, Cate JHD (2012) Structural basis for substrate targeting and catalysis by fungal polysaccharide monooxygenases. Structure 20:1051-1061

Lin H, Shen Q, Zhan J-M, Wang Q, Zhao Y-H (2013) Evaluation of bacterial expansin EXLX1 as a cellulase synergist for the saccharification of lignocellulosic agro-industrial wastes. PLoS ONE 8:e75022
Lombard V, Ramulu HG, Drula E, Coutinho PM, Henrissat B (2014) The carbohydrate-active enzymes database (CAZy) in 2013. Nucleic Acids Res D490-D495

Longoni P, Rodolfi M, Pantaleoni L, Doria E, Concia L, Picco AM, Cella R (2012) Functional analysis of the degradation of cellulosic substrates by a Chaetomium globosum endophytic isolate. Appl Environ Microbiol 78:3693-3705

Lynd LR, Laser MS, Brandsby D, Dale BE, Davison B, Hamilton R, Himmel M, Keller M, McMillan JD, Sheehan J, Wyman CE (2008) How biotech can transform biofuels. Nat Biotechnol 26: $169-172$

Martinez D, Challacombe J, Morgenstern I, Hibbett D, Schmoll M, Kubicek CP, Ferreira P, Ruiz-Duenas FJ, Martinez AT, Kersten P, Hammel KE, Vanden Wymelenberg A, Gaskell J, Lindquist E, Sabat G, Splinter BonDurant S, Larrondo LF, Canessa P, Vicuna R, Yadav J, Doddapaneni H, Subramanian V, Pisabarro AG, Lavín JL, Oguiza JA, Master E, Henrissat B, Coutinho PM, Harris P, Magnuson JK, Baker SE, Bruno K, Kenealy W, Hoegger PJ, Kües U, Ramaiya P, Lucas S, Salamov A, Shapiro H, Tu H, Chee CL, Misra M, Xie G, Teter S, Yaver D, James T, Mokrejs M, Pospisek M, Grigoriev IV, Brettin T, Rokhsar D, Berka R, Cullen D (2009) Genome, transcriptome, and secretome analysis of wood decay fungus Postia placenta supports unique mechanisms of lignocellulose conversion. Proc Natl Acad Sci U S A 106:1954-1959

Phillips CM, Beeson WT, Cate JH, Marletta MA (2011a) Cellobiose dehydrogenase and a copper-dependent polysaccharide monooxygenase potentiate cellulose degradation by Neurospora crassa. ACS Chem Biol 6:1399-1406

Phillips CM, Iavarone AT, Marletta MA (2011b) Quantitative proteomic approach for cellulose degradation by Neurospora crassa. J Proteome Res 10:4177-4185

Quinlan RJ, Sweeney MD, Lo Leggio L, Otten H, Poulsen JCN, Johansen KS, Krogh KBRM, Jørgensen CI, Tovborg M, Anthonsen A, Tryfona T, Walter CP, Dupree P, Xu F, Davies GJ, Walton PH (2011) Insights into the oxidative degradation of cellulose by a copper metalloenzyme that exploits biomass components. Proc Natl Acad Sci U S A 108:15079-15084

Reese ET, Siu RGH, Levinson HS (1950) The biological degradation of soluble cellulose derivatives and its relationship to the mechanism of cellulose hydrolysis. J Bacteriol 59:485-497

Rudolf A, Baudel H, Zacchi G, Hahn-Hägerdal B, Lidén G (2008) Simultaneous saccharification and fermentation of steampretreated bagasse using Saccharomyces cerevisiae TMB3400 and Pichia stipitis CBS6054. Biotechnol Bioeng 99:783-790

Suwannarangsee S, Bunterngsook B, Arnthong J, Paemanee A, Thamchaipenet A, Eurwilaichitr L, Laosiripojana N, Champreda V (2012) Optimisation of synergistic biomass-degrading enzyme systems for efficient rice straw hydrolysis using an experimental mixture design. Bioresour Technol 119:252-261

Tian C, Beeson WT, Iavarone AT, Sun J, Marletta MA, Cate JHD, Glass NL (2009) Systems analysis of plant cell wall degradation by the model filamentous fungus Neurospora crassa. Proc Natl Acad Sci U S A 106:22157-22162

Vaaje-Kolstad G, Westereng B, Horn SJ, Liu Z, Zhai H, Sørlie M, Eijsink VGH (2010) An oxidative enzyme boosting the enzymatic conversion of recalcitrant polysaccharides. Science 330:219-222

Vanden Wymelenberg A, Gaskell J, Mozuch M, Kersten P, Sabat G, Martinez D, Cullen D (2009) Transcriptome and secretome analyses of Phanerochaete chrysosporium reveal complex patterns of gene expression. Appl Environ Microbiol 75:4058-4068

Westereng B, Ishida T, Vaaje-Kolstad G, Wu M, Eijsink VGH, Igarashi K, Samejima M, Ståhlberg J, Horn SJ, Sandgren M (2011) The putative endoglucanase PcGH61D from Phanerochaete chrysosporium is a metal-dependent oxidative enzyme that cleaves cellulose. PLoS ONE 6:e27807 
Wu M, Beckham GT, Larsson AM, Ishida T, Kim S, Payne CM, Himmel ME, Crowley MF, Horn SJ, Westereng B, Igarashi K, Samejima M, Ståhlberg J, Eijsink VGH, Sandgren M (2013) Crystal structure and computational characterization of the lytic polysaccharide monooxygenase GH61D from the basidiomycota fungus Phanerochaete chrysosporium. J Biol Chem 288:1282812839
Yang B, Willies DM, Wyman CE (2006) Changes in the enzymatic hydrolysis rate of Avicel cellulose with conversion. Biotechnol Bioeng 94:1122-1128

Zhou Q, Lv X, Zhang X, Meng X, Chen G, Liu W (2011) Evaluation of swollenin from Trichoderma pseudokoningii as a potential synergistic factor in the enzymatic hydrolysis of cellulose with low cellulase loadings. World J Microbiol Biotechnol 27:1905-1910 